\title{
Peripheral B Cells May Serve as a Reservoir for Persistent Hepatitis C Virus Infection
}

\author{
Masahiko Ito $^{a}$ Atsuko Masumi $^{\mathrm{a}}$ Keiko Mochida ${ }^{\mathrm{b}}$ Hiroshi Kukihara ${ }^{\mathrm{c}}$

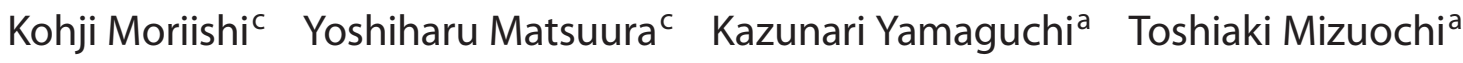 \\ Departments of ${ }^{\mathrm{a}}$ Research on Blood and Biological Products, and ${ }^{\mathrm{b}}$ Bacterial Pathogenesis and Infection, National \\ Institute of Infectious Diseases, Tokyo, and ' Department of Molecular Virology, Research Institute for Microbial \\ Diseases, Osaka University, Suita, Japan
}

\section{Key Words}

Hepatitis $C$ virus $\cdot B$ cells $\cdot$ Retinoic acid-inducible gene-I $\cdot$ Interferon promoter-stimulator-1 $\cdot$ Interferon regulatory factor-3 $\cdot$ Interferon $\beta$

\begin{abstract}
A recent study by our group indicated that peripheral B cells in chronic hepatitis $\mathrm{C}(\mathrm{CHC})$ patients are infected with hepatitis $C$ virus (HCV). This raised the logical question of how HCV circumvents the antiviral immune responses of $B$ cells. Because type I interferon (IFN) plays a critical role in the innate antiviral immune response, IFN $\beta$ expression levels in peripheral $\mathrm{B}$ cells from $\mathrm{CHC}$ patients were analyzed, and these levels were found to be comparable to those in normal $B$ cells, which suggested that HCV infection failed to trigger antiviral immune responses in B cells. Sensing mechanisms for invading viruses in host immune cells involve Toll-like receptor-mediated and retinoic acid-inducible gene-I (RIG-I)mediated pathways. Both pathways culminate in IFN regulatory factor-3 (IRF-3) translocation into the nucleus for IFN $\beta$ gene transcription. Although the expression levels of RIG-I and its adaptor molecule, IFN promoter-stimulator-1, were substantially enhanced in CHC B cells, dimerization and subsequent nuclear translocation of IRF-3 were not detectable. TANK-binding kinase-1 (TBK1) and ІКB kinase $\varepsilon$ (IKK $\varepsilon$ ) are es-
\end{abstract}

sential for IRF-3 phosphorylation. Constitutive expression of both kinases was markedly enhanced in CHC B cells. However, reduced expression of heat shock protein of $90 \mathrm{kDa}$, a TBK1 stabilizer, and enhanced expression of SIKE, an IKK $\varepsilon$ suppressor, were observed in $\mathrm{CHC} B$ cells, which might suppress the kinase activity of TBK1/IKK $\varepsilon$ for IRF-3 phosphorylation. In addition, the expression of vesicle-associated membrane protein-associated protein- $C$, a putative inhibitor of $\mathrm{HCV}$ replication, was negligible in $B$ cells. These results strongly suggest that HCV utilizes $B$ cells as a reservoir for persistent infection.

Copyright $\odot 2010$ S. Karger AG, Basel

\section{Introduction}

Hepatitis $\mathrm{C}$ virus (HCV) is an enveloped positivestranded RNA virus that belongs to the Flaviviridae family [1]. It is responsible for public health problems worldwide and affects nearly 200 million people [2]. The liver is regarded as the primary target of HCV infection; however, HCV infection is also associated with B cell lymphoproliferative disorders such as mixed cryoglobulinemia and B cell non-Hodgkin lymphoma $[3,4]$. In fact, epidemiological evidence suggests a close link between chronic HCV infection and B cell non-Hodgkin lymphoma [5,

\section{KARGER}

Fax +4161306 1234 E-Mail karger@karger.ch www.karger.com

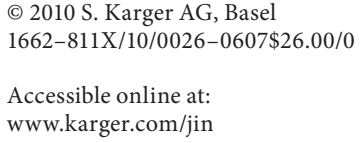

Dr. Toshiaki Mizuochi

Department of Research on Blood and Biological Products

National Institute of Infectious Diseases

4-7-1 Gakuen, Musashi-Murayama, Tokyo 208-0011 (Japan)

Tel. +81 42561 0771, ext. 3243, Fax +81 42562 7875, E-Mail miz@ @ih.go.jp 
6]. A pathogenic role for $\mathrm{HCV}$ in B cell disorders has been further demonstrated by reports showing clinical resolution of the above-mentioned B cell disorders after successful anti-HCV treatment with interferons (IFNs) $[3,7]$. Based on this circumstantial evidence, a possible role for $\mathrm{B}$ cells in HCV pathogenesis has been postulated, although this has not been conclusively demonstrated.

A body of evidence suggests that HCV RNA replication occurs in a variety of extrahepatic cells, including peripheral dendritic cells, monocytes and macrophages [8-10]. It has also been suggested that HCV preferentially infects B cells that express CD81, a putative HCV receptor molecule [11-14]. A recent study by our group verified that peripheral CD19+ B cells in chronic hepatitis C (CHC) patients were infected with $\mathrm{HCV}$, which suggested a new viral reservoir during the course of natural HCV infection in humans [15]. Thus, we assume that HCV has an escape strategy for persistent infection of B cells.

Foy et al. [16] found that nonstructural (NS) HCV proteins could inhibit the activation of early signaling pathways, such as Toll-like receptor 3 (TLR3)- and retinoic acid-inducible gene-I (RIG-I)-mediated pathways, which lead to IFN $\beta$ production. These results indicated that HCV NS3/4A serine protease blocked IFN regulatory factor-3 (IRF-3) activation upon HCV infection in the human hepatoma cell line $\mathrm{HuH}-7$. Subsequent studies have shown that NS3/4A blocks IFN promoter-stimulator-1 (IPS-1)-mediated signaling pathways by cleaving the IPS1 molecule and impeding downstream IRF-3 activation [17]. Thus, HCV apparently has a strategy to evade host innate immunity. However, recent studies by Dansako et al. $[18,19]$ found that the effects of HCV NS3/4A protease on IFN production depended on the cell lines used, because a non-neoplastic human hepatocyte cell line, PH5CH8 [20], retained both TLR3- and RIG-I-mediated pathways, in contrast to HuH-7 cells, which lack the former pathway [21]. However, no studies have examined the effects of HCV infection on IFN responses of nonhepatic cell lines.

In this study, we aimed to understand the mechanisms by which $\mathrm{HCV}$ evades innate immune responses in $\mathrm{CHC}$ $\mathrm{B}$ cells. We found that the antiviral immune response, represented by IFN $\beta$ induction, was severely impaired in $\mathrm{B}$ cells of $\mathrm{CHC}$ patients. Our results strongly suggest that the IRF-3 activation cascade is impeded in B cells upon $\mathrm{HCV}$ infection. Thus, IFN $\beta$ gene transcription is not augmented, which may result in failed IFN $\beta$-inducible antiviral responses in CHC B cells. Furthermore, the expression of vesicle-associated membrane protein-associated protein-C (VAP-C), a putative inhibitor of HCV rep- lication, was negligible in B cells. These results support the notion that HCV can successfully reside in B cells, resulting in persistent infection. This is the first study describing analysis of the suppressive effects of HCV infection on antiviral innate immunity in peripheral $\mathrm{B}$ cells. Thus, this study offers new insights into the role of $\mathrm{B}$ cells in the pathogenesis of $\mathrm{HCV}$.

\section{Methods}

Patients and Samples

A total of $24 \mathrm{CHC}$ patients were enrolled in this study, with the following characteristics: 14 males and 10 females; mean age 62.4 \pm 7.4 years; mean serum ALT levels $67.5 \pm 36.0 \mathrm{IU} / \mathrm{l}$; mean serum AST levels $66.7 \pm 34.3 \mathrm{IU} / \mathrm{l} ; 21$ patients with HCV genotype $1 \mathrm{~b}$ and 3 with HCV genotype $2 \mathrm{a}$, and mean HCV RNA 1,752 $\pm 1,188$ $\mathrm{KIU} / \mathrm{ml}$. All cases were confirmed to be negative for other viral infections, including hepatitis B virus and human immunodeficiency virus. The study protocols were approved by the Review Board of the National Institute of Infectious Diseases. All donors gave written informed consent. Controls were healthy blood donors at the Tokyo Red Cross Blood Center (Tokyo, Japan) who were confirmed to be negative for $\mathrm{HCV}$, hepatitis B virus and human immunodeficiency virus.

Peripheral blood mononuclear cells (PBMCs) were isolated by Ficoll-Hypaque (Pharmacia Biotech, Quebec, Que., Canada) density gradient centrifugation. CD19+ B lymphocytes were isolated from PBMCs by negative selection (B Cell Isolation Kit II, human; Miltenyi, Auburn, Calif., USA). The purity of isolated B cells was generally $>95 \%$, as assessed by flow cytometry.

Semiquantitative Real-Time PCR

Total RNA was extracted from lymphoid cells using Isogen (Nippon Gene Co. Ltd., Tokyo, Japan). cDNA was synthesized using SuperScript III Reverse Transcriptase (Invitrogen, Carlsbad, Calif., USA) with oligo(dT)12-18 primer (Invitrogen). PCR amplification was performed using SYBR Premix Ex Taq ${ }^{\mathrm{TM}}$ II (Takara Shuzo, Kyoto, Japan) with gene-specific primers (Bex Co. Ltd., Tokyo, Japan) available in the public database RTPrimerDB [22] under the codes 3542 for IFN $\beta$ and 3539 for GAPDH, and the Universal Probe Library Assay Design Center (https://www. roche-applied-science.com/sis/rtpcr/upl/index.jsp; Roche Applied Science) as follows: IPS-1 (No. 19, 04686926001), TIR domain-containing adaptor inducing IFN (TRIF; No. 37, 04687957001), suppressor of IкB kinase $\varepsilon$ (IKK $\varepsilon$ ) (SIKE; No. 56, 04688538001), heat-shock protein of $90 \mathrm{kDa}$ (Hsp90; No. 25, 04686993001) and DEAD (Asp-Glu-Ala-Asp) box polypeptide 3, X-linked (DDX3X; No. 69, 04688686001). The primer sequences for RIG-I were 5'-GTG CAA AGC CTT GGC ATG T-3' (forward) and 5'-TGG CTT GGG ATG TGG TCT ACT C-3' (reverse) [23], and for TLR3 they were $5^{\prime}$-GTT ACG AAG AGG CTG GAA TGG T-3' (forward) and 5'-GCC AGG AAT GGA GAG GTC TAG A-3' (reverse) [24].

Real-time PCR was carried out for 45 cycles at $94^{\circ} \mathrm{C}$ for $1 \mathrm{~min}$ and at $60^{\circ} \mathrm{C}$ for $25 \mathrm{~s}$ (two-step PCR) using a Light Cycler (Roche Diagnostics, Basel, Switzerland). Amplification of predicted fragments was confirmed by melt curve analysis and gel electropho- 
resis. Standard curves were established with 10 -fold serial dilutions of amplified products. Measured amounts of each mRNA were normalized to GAPDH mRNA. mRNA expression levels in normal B cells were arbitrarily defined as 1.0.

\section{Immunoblot Analysis}

To extract whole-cell proteins, cell pellets were suspended in modified RIPA buffer [150 mM NaCl, 50 mM Tris-Cl ( $\mathrm{pH} 7.4$ ), 1 mM EDTA, $1.0 \%$ NP-40, $0.5 \%$ sodium deoxycholic acid and $0.1 \%$ SDS] containing Halt protease inhibitor cocktail (Pierce, Rockford, Ill., USA) and Halt phosphatase inhibitor cocktail (Pierce; $2 \times 10^{7}$ cells $/ \mathrm{ml}$ ). After 20 min of incubation on ice, cell extracts were centrifuged at $12,000 \mathrm{~g}$ for $10 \mathrm{~min}$ at $4^{\circ} \mathrm{C}$, transferred to other tubes and stored at $-80^{\circ} \mathrm{C}$. Nuclear and cytoplasmic proteins were separated using a Nuclear Extraction Kit (Active Motif, Carlsbad, Calif., USA) according to the manufacturer's protocol. Protein concentration was determined using the $\mathrm{BCA}^{\mathrm{TM}}$ Protein Assay Kit - Reducing Agent Compatible (Pierce). Samples (wholecell extract, $1 \mathrm{~g}$; fractionated extract, $2 \times 10^{5}$ cells) were loaded onto 7.5 or $12.5 \%$ SDS acrylamide gels (Real Gel Plate; Bio Craft, Tokyo, Japan), followed by transfer to polyvinylidene difluoride membranes. Membranes were blocked for $1 \mathrm{~h}$ at room temperature using Block Ace ${ }^{\mathrm{TM}}$ (Dainippon Sumitomo Pharma Co. Ltd., Osaka, Japan). They were then sequentially probed with primary and secondary antibodies at $4^{\circ} \mathrm{C}$ overnight and for $1 \mathrm{~h}$ at room temperature, respectively.

For primary antibodies, we used anti-IFN rabbit polyclonal antibody (ab9662, 1/1,000 dilution; Abcam Inc., Cambridge, Mass., USA), anti-ACTB ( $\beta$-actin) rabbit polyclonal antibody (4967, 1/1,000 dilution; Cell Signaling Technology, Danvers, Mass., USA), anti-TLR3 rabbit polyclonal antibody (ab62566, 1/1,000 dilution; Abcam), anti-TRIF rabbit polyclonal antibody (4596, 1/1,000 dilution; Cell Signaling Technology), anti-RIG-I rabbit polyclonal antibody (29010, 1/100 dilution; Immuno-Biological Laboratories Co. Ltd., Gunma, Japan), anti-IPS-1 rabbit polyclonal antibody (AT107, 1/2,000 dilution; Alexis Biochemicals, Farmingdale, N.Y., USA), anti-IRF-3 rabbit polyclonal antibody (18781, 1/100 dilution; Immuno-Biological Laboratories), anti-GAPDH mouse monoclonal antibody [5G4(6C5), 1/9,000 dilution; HyTest Ltd., Turku, Finland], anti-PARP-1 mouse monoclonal antibody (AM30, 1/500 dilution; Calbiochem, San Diego, Calif., USA), antiTANK-binding kinase-1 (TBK1) rabbit polyclonal antibody (3504, 1/1,000 dilution; Cell Signaling Technology) and anti-IKKe rabbit polyclonal antibody (ab7891, 1/500 dilution; Abcam). Anti-VAP-C rabbit polyclonal antibody $(2.66 \mathrm{~g} / \mathrm{ml})$ was produced by a group of the authors (H.K., K. Moriishi and Y.M.).

The secondary antibodies used were horseradish peroxidasecoupled donkey anti-rabbit Ig (NA934, 1/10,000 dilution; GE Healthcare Ltd.; UK, Buckinghamshire, UK) and horseradish peroxidase-coupled sheep anti-mouse Ig (NA931, 1/10,000 dilution; GE Healthcare UK). Protein bands were detected using ECL Plus ${ }^{\mathrm{TM}}$ Western Blotting Detection Reagents (GE Healthcare UK) and a LAS-3000 Image Analyzer (Fuji Film, Tokyo, Japan). Densitometric analysis was performed within a linear range using Image Gauge (Fuji Film). The density of each band (the amount of protein) was normalized against that of the corresponding $\beta$-actin.

Native PAGE for IRF-3 Dimer Detection

Native PAGE was performed using 7.5\% SDS acrylamide gels (Real Gel Plate; Bio Craft). Gels were prerun with $25 \mathrm{~mm}$ Tris-Cl
(pH 8.4) and $192 \mathrm{~mm}$ glycine with and without $0.2 \%$ deoxycholate in the cathode and anode chambers, respectively, for $30 \mathrm{~min}$ at 40 $\mathrm{mA}$. Samples were extracted in lysis buffer $\left(3 \times 10^{7}\right.$ cells $/ \mathrm{ml} ; 50$ $\mathrm{mM}$ Tris-Cl, pH 8.0, 1\% NP40, $150 \mathrm{mM} \mathrm{NaCl}$ ) containing Halt protease inhibitor cocktail and Halt phosphatase inhibitor cocktail, mixed with equal volumes of Tris-glycine native sample buffer ( $2 \times$; Invitrogen), applied to the gel and electrophoresed for 60 $\mathrm{min}$ at $25 \mathrm{~mA}$.

Immunoblotting was performed as described above. As a positive control for IRF-3 dimerization, HeLa cells were added with $100 \mathrm{~g} / \mathrm{ml}$ polyriboinosinic-polyribocytidylic acid (poly I:C; kindly provided by Toray Co. Ltd., Tokyo, Japan). Three hours after incubation, cells were harvested and cell lysates were prepared as described above.

\section{Poly I:C Transfection}

CD19+ B lymphocytes isolated from PBMCs were cultured in RPMI-1640 medium containing 10\% FCS, 2 mM L-glutamine, $1 \mathrm{mM}$ HEPES, $0.05 \mathrm{~mm} \beta$-mercaptoethanol, penicillin and streptomycin in a flat-bottom 96 -well plate for $3 \mathrm{~h}\left(2.5 \times 10^{6}\right.$ cells/ well). To activate the RIG-I-mediated pathway, cells were transfected with $10 \mu \mathrm{g} / \mathrm{ml}$ poly I:C using Poly(I:C)/LyoVec (Invivogen, San Diego, Calif., USA). After 18 h of culture, transfected or nontransfected cells were dissolved in Isogen (Nippon Gene) for semiquantitative real-time PCR assay. Three independent triplicate transfection experiments were performed in order to verify the reproducibility of the results.

\section{Statistics}

Unpaired (two-tailed) Student's t tests were applied at the 95\% confidence level $(\mathrm{p}<0.05)$ using Prism (version 4; GraphPad Software Inc., San Diego, Calif., USA) in all cases.

\section{Results}

\section{Impaired IFN Responses in Peripheral B Cells of CHC Patients}

We recently demonstrated that $\mathrm{HCV}$ infected and may have replicated in peripheral B cells of CHC patients [15]. This implied that HCV may have evaded the immune response by B cells, resulting in persistent infection. Because the induction of type I IFNs, including IFN $\beta$, is crucial for host defense against invading viruses, we first examined constitutive IFN $\beta$ expression levels in peripheral B cells of CHC patients. As shown in figure 1a, IFN $\beta$ mRNA expression levels were not augmented in $\mathrm{CHC} B$ cells compared with normal B cells. The results of Western blotting analysis (fig. 1b) indicated that constitutive IFN $\beta$ protein expression levels were not enhanced in $B$ cells of CHC patients, which supported the finding of unaltered IFN $\beta$ mRNA expression.

We then stimulated normal and $\mathrm{CHC} B$ cells using poly I:C transfection, which triggers RIG-I- and melanoma differentiation-associated gene-5-mediated IFN $\beta$ path- 
Fig. 1. IFN $\beta$ expression in $\mathrm{CHC} B$ cells. Fractionation of CD19+ B cells from PBMCs was performed as described in Methods. a IFN $\beta$ mRNA expression levels in CD19+ B cells isolated from normal individuals $(\mathrm{n}=4)$ and $\mathrm{CHC}$ patients $(\mathrm{n}=7)$ were measured in duplicate by quantitative real-time RT-PCR and normalized against those of the housekeeping gene GAPDH. mRNA expression levels in normal B cells were arbitrarily defined as 1.0. b Whole-cell extracts prepared from CD19+ B cells isolated from normal individuals $(n=3)$ and CHC patients $(n=3)$ were subjected to SDS-PAGE and analyzed by immunoblotting using anti-IFN $\beta$ and anti-ACTB antibodies. Relative IFN $\beta$ protein expression levels normalized against $\beta$-actin expression are shown. c CD19+ B cells isolated from normal individuals $(\mathrm{n}=$ 3) or CHC patients $(n=3)$ were transfected with poly I:C $(10 \mathrm{~g} / \mathrm{ml})$. Eighteen hours after transfection, cells were harvested and total RNA was isolated. IFN $\beta$ mRNA expression levels were measured in duplicate using quantitative real-time RT-PCR and normalized against those of the housekeeping gene GAPDH. mRNA expression levels in untransfected normal or CHC B cells were arbitrarily defined as 1.0. Representative results from at least 2 independent experiments with similar results are shown.

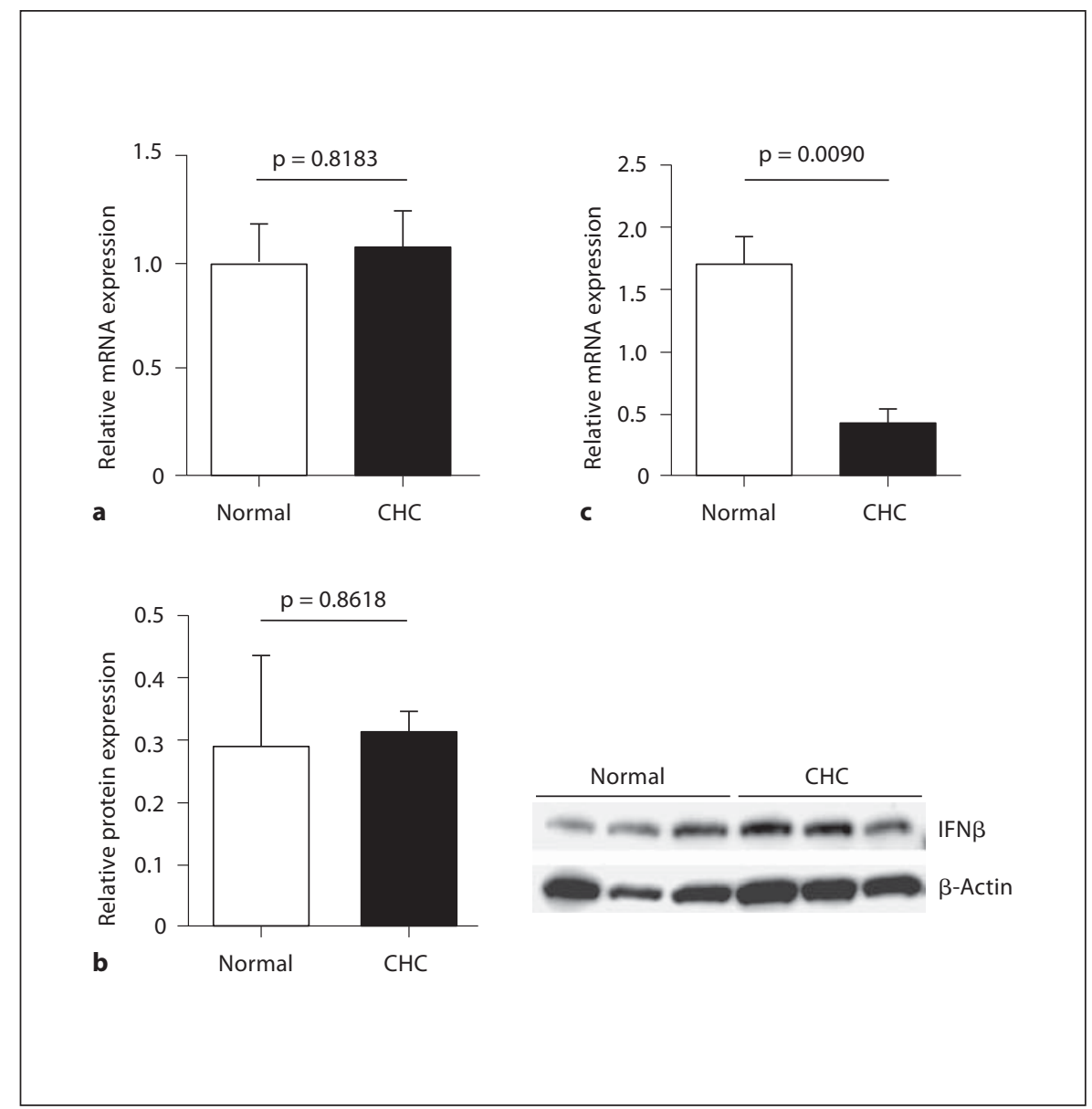

ways. As shown in figure 1c, IFN $\beta$ mRNA expression levels in CHC B cells were much lower than those in normal $\mathrm{B}$ cells, suggesting that $\mathrm{CHC} B$ cells are defective with regard to IFN $\beta$ production upon stimulation with the intracellular delivery of poly I:C. In addition, the expression levels of IFN-stimulated genes, such as ISG-15 and ISG56 , in CHC B cells were also much lower than those in normal B cells upon poly I:C stimulation (data not shown).

Taken together, these results indicate that chronic $\mathrm{HCV}$ infection fails to induce an IFN $\beta$ response in $\mathrm{CHC}$ $B$ cells. Subsequent experiments were designed to elucidate the underlying mechanism(s) by which $\mathrm{HCV}$ interrupted the IFN responses in CHC B cells.

\section{Expression Levels of HCV Sensor Molecules in}

Peripheral B Cells of CHC Patients

We next examined the gene expression levels in peripheral B cells of two major viral sensors, TLR3 and RIG-I, as well as their corresponding adaptor molecules,
TRIF and IPS-1, which are indispensable for initiating innate immune responses [25]. As shown in figure 2, TLR3, TRIF, RIG-I and IPS-1 expression levels were significantly enhanced in peripheral B cells of CHC patients. Expression of another cytoplasmic sensor molecule, melanoma differentiation-associated gene-5, was also enhanced (data not shown). These results demonstrate that the expression levels of cytoplasmic virus sensors as well as their adaptors are constitutively augmented in $\mathrm{CHC} \mathrm{B}$ cells.

\section{Expression, Dimerization and Nuclear Translocation of IRF-3 in CHC B Cells}

The IRF-3 activation cascade, including phosphorylation, dimerization and nuclear translocation, is essential for IFN $\beta$ gene transcription [26]. We found that constitutive IRF-3 expression levels in CHC B cells were significantly lower than those in normal B cells $(p=0.0018)$ as assessed by Western blotting (fig. 3a). Furthermore, IRF- 


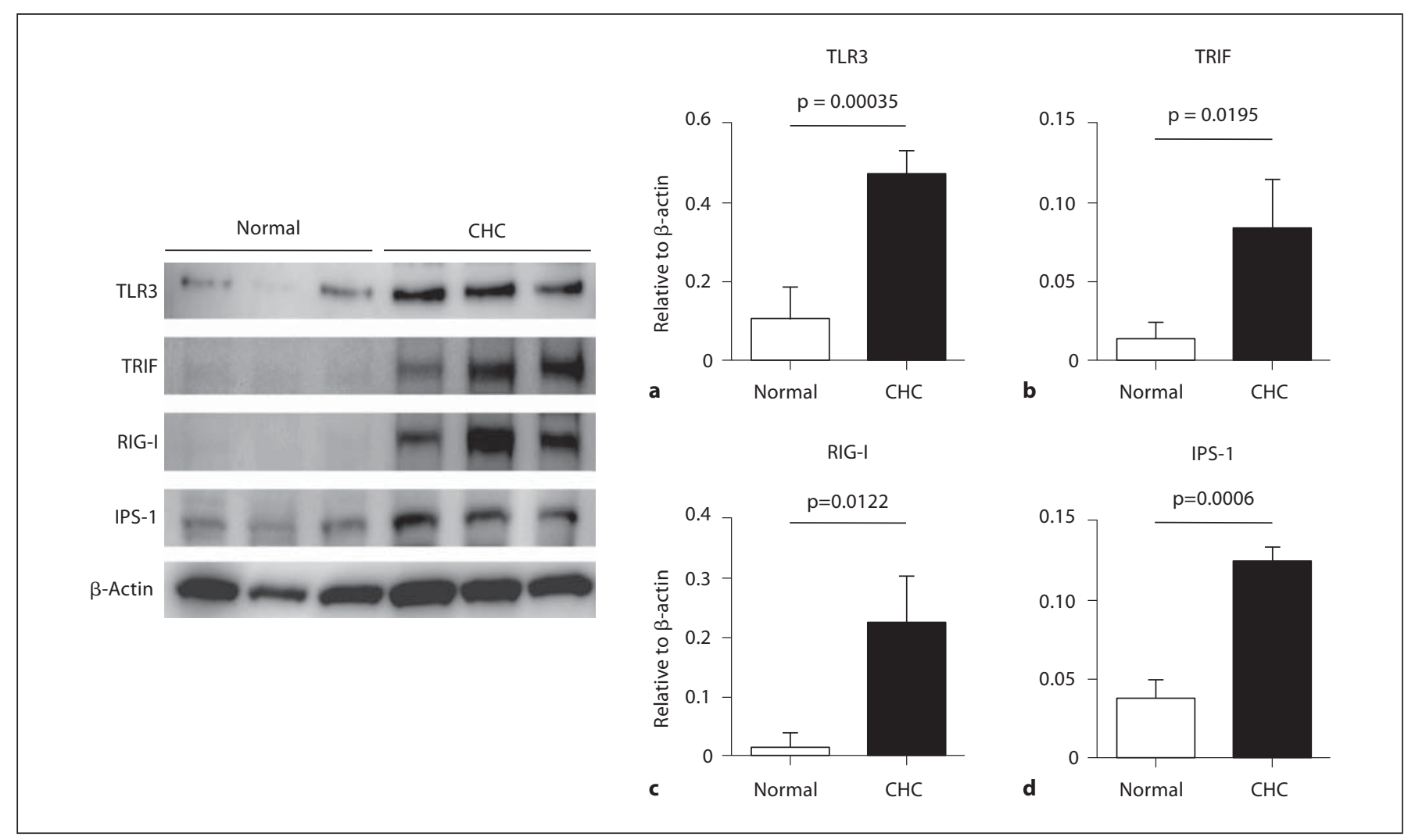

Fig. 2. Expression levels of HCV sensor and adaptor molecules in CHC B cells. Whole-cell extracts prepared from CD19+ B cells isolated from normal individuals $(n=3)$ and CHC patients $(n=3)$ were subjected to SDSPAGE and analyzed by immunoblotting using anti-TLR3, anti-TRIF, anti-RIG-I, anti-IPS-1 and control antiACTB antibodies. Relative protein expression levels normalized against $\beta$-actin expression are shown.

3 dimerization assessed by native PAGE was not observed in $\mathrm{CHC} \mathrm{B}$ cells (fig. 3b). Consequently, IRF-3 nuclear translocation did not occur in CHC B cells (fig. 3c). Thus, these results indicate that the IRF-3 activation cascade does not proceed in $\mathrm{CHC}$ B cells, which may explain the lack of IFN $\beta$ responses to $\mathrm{HCV}$ infection.

\section{Cleavage of IPS-1 in CHC B Cells}

Several lines of evidence have indicated an essential role for the adaptor molecule IPS-1, also called Cardif, MAVS or VISA, which acts downstream of RIG-I in the IRF-3 signaling pathway [27]. Recent studies have confirmed that $\mathrm{HCV}$ can cleave IPS- 1 via its NS3/4A protease activity [28]. As a result of this proteolytic cleavage, IPS-1 is dislodged from the mitochondria and becomes an inactive cytosolic fragment. This causes the failure of downstream signaling for IRF-3 activation. Therefore, we examined IPS-1 cleavage in CHC B cells by native PAGE. As shown in figure 4 , IPS-1 cleavage was incomplete, and a substantial amount of uncleaved (intact) IPS-1 was detected. Thus, we concluded that impaired IRF-3 activation cannot be solely explained by IPS-1 cleavage in CHC $B$ cells. These results suggest either that the NS3/4A protease is not expressed in CHC B cells or that IPS- 1 in B cells is resistant to this protease. Because NS3 molecules were detected in CHC B cells by Western blotting [15], the latter seems to be more likely.

\section{Stabilization or Inhibition of TBK1/IKKE Kinase Activity in CHC B Cells}

Two protein kinases, TBK1 and IKKe, which are both located downstream of IPS-1, are essential for IFN $\beta$ production via IRF-3 phosphorylation [29]. Interestingly, the constitutive expression levels of both kinases were markedly enhanced in CHC B cells compared with those in normal B cells (fig. 5), although the downstream IRF-3 activation cascade was severely impaired, as shown in figure 3. 


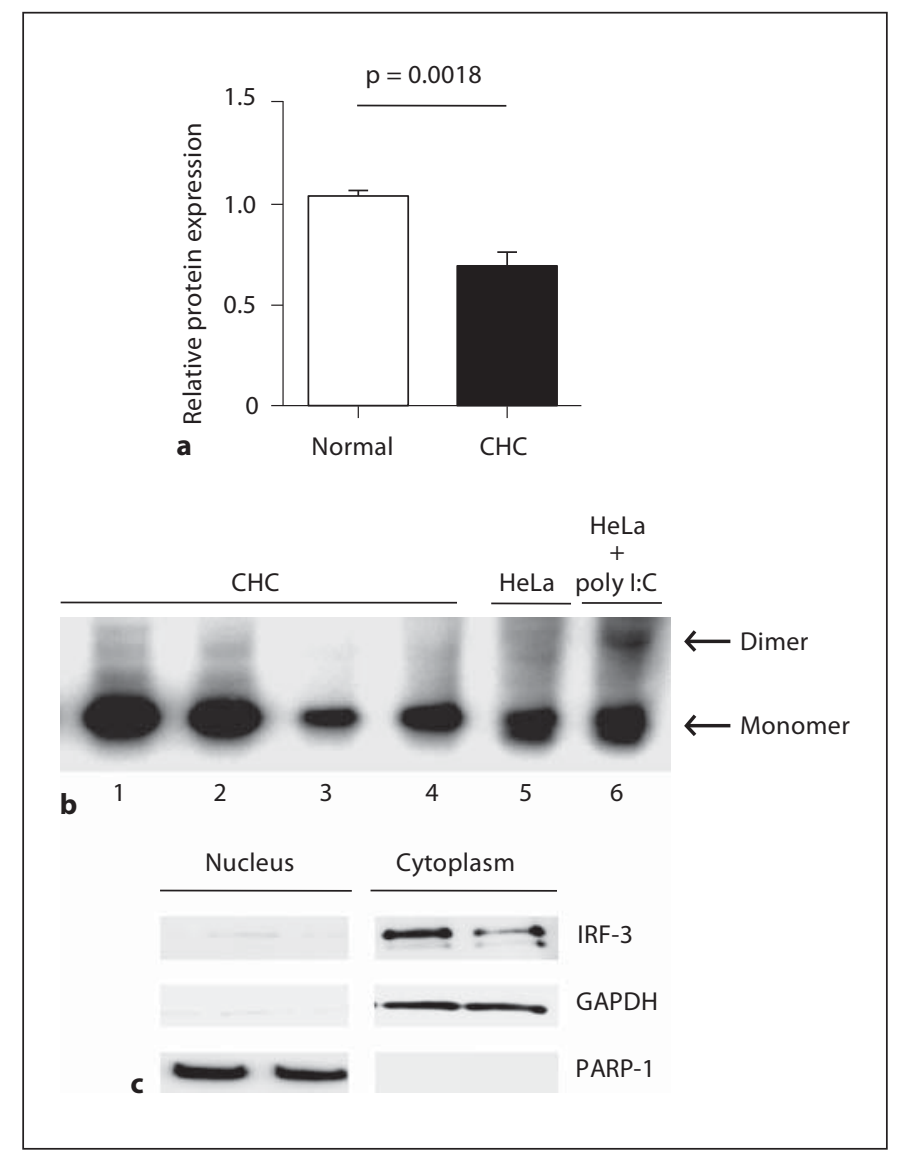

Fig. 3. Expression, dimerization and nuclear translocation of IRF3 in CHC B cells. a Whole-cell extracts prepared from CD19+ B cells isolated from randomly selected normal individuals $(\mathrm{n}=3)$ and $\mathrm{CHC}$ patients $(\mathrm{n}=3)$ were subjected to SDS-PAGE and analyzed by immunoblotting using anti-IRF-3 and anti-ACTB antibodies. Relative protein expression levels of IRF-3 normalized against $\beta$-actin expression are shown. $\mathbf{b}$ Dimerization of IRF-3 in CD19+ B cells isolated from CHC patients $(n=4)$ were analyzed by native PAGE as described in Methods. As a positive control to detect IRF-3 dimer formation, cell extracts from HeLa cells stimulated with poly I:C were applied (lane 6). c Nuclear and cytoplasmic proteins were isolated from $\mathrm{CD} 19+\mathrm{B}$ cells of $\mathrm{CHC}$ patients $(n=2)$ as described in Methods. Samples were subjected to SDSPAGE and analyzed by immunoblotting using anti-IRF-3, antiGAPDH (cytoplasmic marker protein) and anti-PARP-1 (nuclear marker protein) antibodies.

Huang et al. [30] identified a protein called SIKE that interacts with IKK $\varepsilon$ and TBK1 and has an inhibitory effect on the IRF-3 activation pathway. Yang et al. [31] demonstrated that Hsp90 was important for stabilizing TBK1 and promoting IRF-3 phosphorylation by TBK1 in response to viral infection. The gene expression levels of

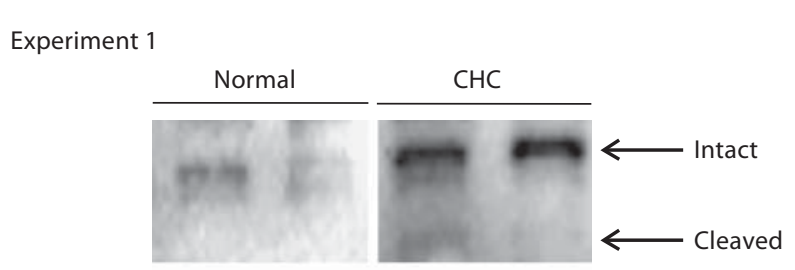

Experiment 2

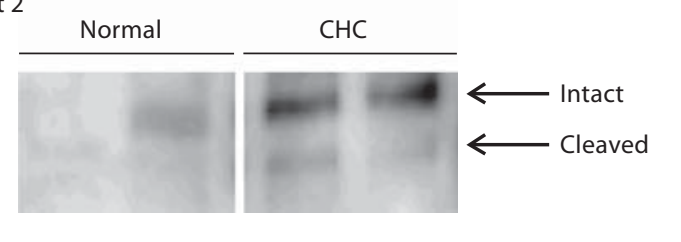

Fig. 4. Cleavage of IPS-1 in CHC B cells. Whole-cell extracts prepared from CD19+ B cells isolated from randomly selected normal individuals $(n=2)$ and CHC patients $(n=2)$ were subjected to SDS-PAGE and analyzed by immunoblotting using anti-IPS-1 antibody. Results of 2 independent experiments are shown.

these two molecules in B cells were analyzed by real-time $\mathrm{PCR}$, as shown in figure 6a. SIKE expression levels were significantly enhanced in CHC B cells $(\mathrm{p}=0.0059)$, while those of Hsp90 were significantly reduced ( $\mathrm{p}=0.001$ ). These results strongly suggest that the kinase activities of TBK1 and IKK $\varepsilon$ are downregulated in CHC B cells, which may be responsible for the failure in IRF-3 activation and subsequent IFN $\beta$ transcription.

The DEAD box helicase DDX3X [32] is a critical component of TBK1-dependent type I IFN induction [33, 34]. As shown in figure 6a, DDX3X expression levels were significantly reduced in CHC B cells $(\mathrm{p}=0.0043)$. This could be just a concomitant observation; however, this result is of interest assuming that HCV has an additional mechanism by which it interferes with IRF-3 activation.

\section{VAP-C Expression in B Cells}

Human VAP subtype A (VAP-A) and subtype B (VAP$B$ ) are essential host factors for $\mathrm{HCV}$ replication because they bind to both NS5A and NS5B [35]. VAP-C is a splicing variant of VAP-B that lacks two thirds of the $\mathrm{C}$ terminus [36, 37]; therefore, it cannot interact with VAP-A, VAP-B or NS5A. A physiological role of VAP-C was recently demonstrated by Kukihara et al. [38], who found that VAP-C inhibited the association between VAP-A/B and NS5B, thereby reducing HCV replication efficiency. Interestingly, VAP-C expression in hepatocytes was found to be negligible, which may be advantageous for 
HCV replication in the liver [38]. These results prompted us to examine VAP-C expression in B cells. As shown in figure 6b, VAP-C was expressed in CD19- cells (i.e. non$\mathrm{B}$ cells), but not in CD19+ B cells. Together with the defect in antiviral immune responses of CHC B cells described above, this observation further supports the notion that $\mathrm{HCV}$ utilizes B cells as a reservoir for persistent infection.

\section{Discussion}

HCV infection of hepatocytes has long been an implicit assumption. However, this does not necessarily imply that hepatocytes are the exclusive target for HCV infection. HCV may seek other cellular compartments as reservoirs in the event that the liver becomes unsuitable for replication, possibly due to cellular destruction caused by the host immune response and/or the development of conditions such as cirrhosis and hepatocellular carcinoma. Our previous study suggested the possibility that HCV persistently infects peripheral B cells [15]. Consequently, we were extremely interested in how $\mathrm{HCV}$ is able to escape host innate immunity and persistently remain in peripheral B cells. The results of this study may provide plausible answers to these questions.

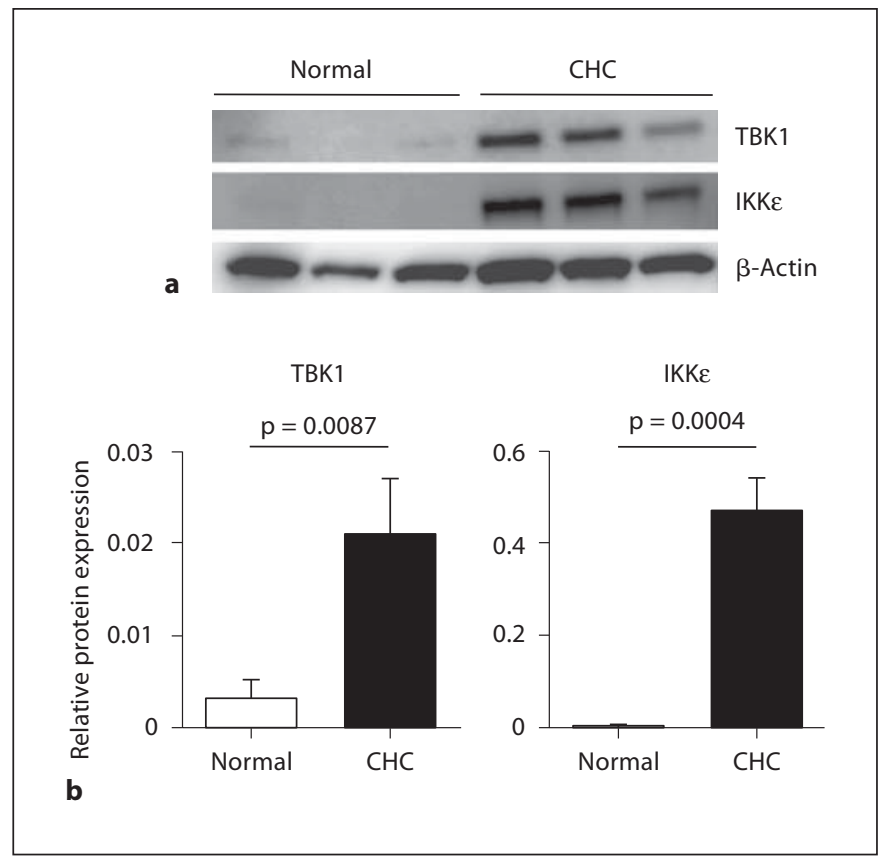

Fig. 5. Expression of TBK1 and IKKe in CD19+ B cells. a Wholecell extracts prepared from CD19+ B cells isolated from normal individuals $(n=3)$ and CHC patients $(n=3)$ were subjected to SDS-PAGE and analyzed by immunoblotting using anti-TBK1, anti-IKK $\varepsilon$ and anti-ACTB antibodies. b Relative protein expression levels of each protein normalized against $\beta$-actin expression are shown.
Fig. 6. Expression of SIKE, Hsp90, DDX3X and VAP-C in CD19+ B cells. a mRNA expression levels of SIKE, Hsp90 and DDX3X in CD19+ B cells isolated from normal individuals $(\mathrm{n}=3-7)$ and CHC patients $(\mathrm{n}=$ $3-5$ ) were measured in duplicate by quantitative real-time RT-PCR and normalized against those of the housekeeping gene GAPDH. mRNA expression levels in normal B cells were arbitrarily defined as 1.0. b Whole-cell extracts prepared from CD19- and CD19+ B cells isolated from normal individuals $(n=3)$ were subjected to SDS-PAGE and analyzed by immunoblotting using anti-VAP-C antibody. Whole-cell extracts from $293 \mathrm{~T}$ cells were used as a positive control.

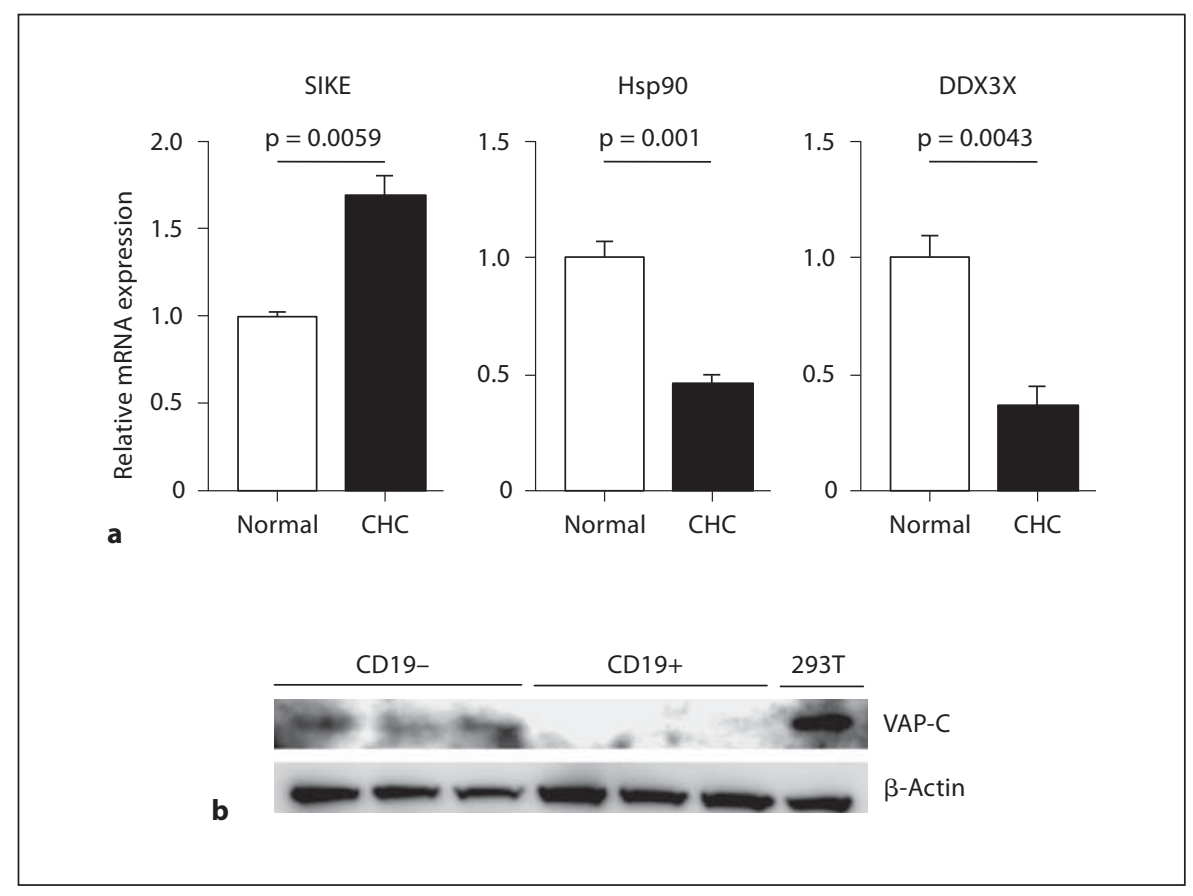


In this study, we observed augmented expression of RIG-I, a cytoplasmic double-stranded RNA sensor molecule, and its adaptor molecule IPS-1 in CHC B cells (fig. 2). To our knowledge, this is the first study describing the enhanced expression of a cytoplasmic HCV sensor in CHC B cells. Miyazaki et al. [39] recently reported similar findings on examining myeloid dendritic cells in $\mathrm{CHC}$ patients, thus suggesting that $\mathrm{HCV}$ infection augments the expression of a cytoplasmic double-stranded RNA sensor regardless of the cell type. The same may be true for expression of the RIG-I adaptor molecule IPS-1, because Miyazaki et al. [39] also reported enhanced IPS1 expression in myeloid dendritic cells in CHC patients. These results support the notion that HCV triggers innate immunity by immune cells, including peripheral $\mathrm{B}$ cells.

The primary cause for the failure to induce innate immunity in CHC B cells appears to be a defect in promoting the IRF-3 activation cascade (fig. 3). $\mathrm{HCV}$ is thought to evade an innate antiviral response by the actions of the viral NS3/4A protease-helicase complex, which inhibits RIG-I signaling via proteolytic cleavage and IPS-1 inactivation [28], thereby preventing its downstream activation (i.e. IRF-3 activation). This hypothesis was essentially derived from in vitro experiments using human hepatoma cell lines such as HuH-7. In the present study, IPS-1 cleavage was analyzed for the first time in peripheral $\mathrm{B}$ cells of CHC patients. The results shown in figure 4 indicate only marginal cleavage of IPS-1 in CHC B cells, such that this could not be the main cause of the defect in downstream IRF-3 activation. We therefore sought additional explanations for the IRF-3 activation defect in CHC B cells.

The results shown in figure 5 indicate markedly enhanced expression of TBK1 and IKKe in CHC B cells compared with normal B cells, thus suggesting that IPS-1 signaling is mainly intact and not completely abolished by $\mathrm{HCV}$ infection as expected. In the present study, it was not possible to identify the mechanism underlying the expression of TBK1 and IKK $\varepsilon$ induced by HCV infection. However, as shown in figure 3, IRF-3 activation was markedly suppressed in CHC B cells. The defect in IRF-3 activation in CHC B cells may be linked to the enhanced expression of SIKE and the reduced expression of Hsp90 (fig. 6a), which together may affect the kinase activities of both TBK1 and IKKe. Consequently, IRF-3 phosphorylation (i.e. the first step of the IRF-3 activation cascade) would not be successfully executed. However, the possibilities that IPS-1 signaling is disrupted along the cascade despite the existence of the signal molecule and/or that
IRF-3 activation is directly blocked by HCV proteins should also be taken into consideration.

It was recently demonstrated that the expression of DDX3X, a DEAD box RNA helicase [32], enhanced IFN $\beta$ promoter induction by TBK1/IKK $\varepsilon$, whereas its knockdown inhibited IRF3 activation [33]. The results shown in figure 6a confirm that DDX3X expression levels were significantly downregulated in CHC B cells, which is in agreement with previous studies. However, Ariumi et al. [40] reported that DDX3X was required for HCV RNA replication, which seems contradictory to our results. We currently do not know the reasons for this discrepancy; however, the fact that in their study they used the HuH-7 hepatoma cell line, while we examined naturally occurring HCV-infected B cells, may account for these conflicting results.

The role of VAP proteins in HCV replication is another interesting aspect. HCV NS5A is associated with a range of cellular proteins, including VAP-A [41], which are involved in cell signaling pathways. VAP-B has been identified as another NS5A-binding protein by screening human libraries using the yeast two-hybrid system with NS5A as bait [35]. Both VAP-A and VAP-B are involved in $\mathrm{HCV}$ replication via interactions with NS5A and NS5B [35], while VAP-C inhibits the association between VAP$\mathrm{A} / \mathrm{B}$ and NS5B, which results in reduced HCV replication efficiency [38]. Therefore, the absence of VAP-C expression in B cells, similar to hepatocytes, may be favorable for HCV replication. This could be another strategy for maintaining persistent $\mathrm{HCV}$ infection in B cells. In fact, our recent study demonstrated that a high copy number of HCV RNA was detected in CHC B cells, but not in $\mathrm{CHC}$ non-B cells [15], suggesting that the absence of VAP-C expression in B cells is, at least in part, responsible for the HCV replication. Further analyses are required to examine if the forced expression of VAP-C could inhibit $\mathrm{HCV}$ replication in B cells.

Several lines of evidence indicate that chronic infection with HCV can induce molecular alterations in lymphocytes that may subsequently play a role in the multistep process of malignant lymphocyte transformation with the induction of clonal B cell expansion. Lymphoid cells from patients with chronic HCV overexpress the antiapoptotic protein Bcl-2 with a high incidence of $t(14 ; 18)$ translocations involving the $b c l-2$ gene $[42,43]$. Our recent study revealed that the expression level of activationinduced cytidine deaminase, which promotes B cell lymphomagenesis by its overexpession [44, 45], in CHC B cells was significantly increased [15]. Furthermore, enhanced expression of putative lymphomagenesis-related 
genes such as cyclin D1, cyclin D2, B aggressive lymphoma gene, serine/threonine kinase 15 and galectin- 3 was observed in CHC B cells [15]. In addition, expression of $\mathrm{HCV}$ core protein and NS3 was detected in CD19+ B cells of $\mathrm{CHC}$ patients [15]. HCV core protein has been demonstrated to promote immortalization in different cell lines as well as being capable of blocking c-myc-induced apoptosis [46]. NS3 has also been shown to promote oncogenic transformation and to interact with p53 and interfere with apoptosis [47]. Thus, persistent infection with HCV via the suppression of innate immunity responses in CHC B cells would cause functional disorders and lead to $B$ cell lymphoma.

Interestingly, it has been shown that interaction between HCV E2 and CD81 on B cells triggers enhanced expression of activation-induced cytidine deaminase, which induces double-strand DNA breaks and hypermutation, specifically in the VH gene of B cells [48]. Stamataki et al. [49] demonstrated that peripheral blood B cells could bind infectious HCV in the cell strain JFH-1. Accordingly, it seems likely that mere interaction between envelope proteins of $\mathrm{HCV}$ and signaling receptors on the surface of $\mathrm{B}$ cells could generate lymphoproliferative disorders.

The difficulty in collecting an adequate number of purified B cells from $\mathrm{CHC}$ patients prevented us from analyzing a large sample size in each experiment, which may weaken the impact of these results. However, in the light of the fact that potentially heterogeneous patient samples were examined in this study, we believe that our considerably homogeneous results do have a certain biological impact. In addition, it may be worth noting that most CHC patients enrolled in this study (21 of 24) were infected with HCV of genotype $1 \mathrm{~b}$, which is prevalent in Asia. It would have been ideal to perform these experiments with different genotypes to observe if this phenomenon is noted across all genotypes or if it is specific only to genotype $1 \mathrm{~b}$. A study enrolling $\mathrm{CHC}$ patients infected with other HCV genotypes will be required in order to draw more robust conclusions, although it is very difficult to enroll such CHC subjects in Japan.

Taken together, the present results strongly suggest that HCV utilizes B cells as an extrahepatic reservoir for persistent infection. Whether the apparent suppression of innate immune responses in $\mathrm{B}$ cells is restricted to $\mathrm{HCV}$ infection or if this is a phenomenon seen in other $\mathrm{B}$ cell tropic viruses such as Epstein-Barr virus is currently unknown. This intriguing question could be answered by further elucidating the suppression mechanisms in $\mathrm{CHC}$ $\mathrm{B}$ cells as well as by investigating innate immune responses in Epstein-Barr virus-infected B cells in future studies.
We assume that memory B cells are the main reservoir of HCV infection because of their long life span. In support of this proposal, one of our current studies indicated that $\mathrm{CD} 19+\mathrm{CD} 27+$ cells (i.e. memory B cells) are recruited to the livers of $\mathrm{CHC}$ patients via interactions between CXCR3 expressed on CD19+CD27+ cells and IP-10 produced in the liver [Mizuochi et al., in press]. This would be a robust strategy for HCV in order to secure sites for long-lasting infection. Interestingly, a recent study by Stamataki et al. [49] indicated that HCV associated with $\mathrm{B}$ cells had the potential to transfect HuH-7.5 in vitro. Our results strongly suggest that such HCV transfection may occur in vivo under physiological conditions. This would offer new therapeutic insights for HCV clearance by eliminating peripheral $\mathrm{B}$ cells with anti-B cell antibodies and drugs such as rituximab in conjunction with a combination therapy using peginterferon and ribavirin.

In conclusion, we propose that peripheral B cells serve as a reservoir for persistent $\mathrm{HCV}$ infection. Based on this proposal and from a therapeutic perspective, it may be beneficial to eliminate peripheral B cells in CHC patients. Together with antiviral treatment to eliminate circulating $\mathrm{HCV}$ in the blood, this could lead to a synergistic effect for $\mathrm{HCV}$ clearance in $\mathrm{CHC}$ patients.

\section{Acknowledgments}

We would like to thank Drs. Miho Suzuki and Kenji Ikebuchi for providing the $\mathrm{CHC}$ blood samples used in this study. We would also like to thank Drs. Koji Onomoto, Mitsutoshi Yoneyama and Takashi Fujita for their valuable suggestions during the course of this study.

This study was supported by Grants-in-Aid from the Ministry of Health, Labour and Welfare, Japan.

References
Suzuki T, Ishii K, Aizaki H, Wakita T: Hepatitis C viral life cycle. Adv Drug Deliv Rev 2007;59:1200-1212.

-2 Lauer GM, Walker BD: Hepatitis C virus infection. N Engl J Med 2001;345:41-52.

3 Agnello V, Mecucci C, Casato M: Regression of splenic lymphoma after treatment of hepatitis C virus infection. N Engl J Med 2002; 347:2168-2170, author reply 2168-2170.

4 Zuckerman E, Zuckerman T, Levine AM, Douer D, Gutekunst K, Mizokami M, Qian DG, Velankar M, Nathwani BN, Fong TL: Hepatitis $\mathrm{C}$ virus infection in patients with B-cell non-Hodgkin lymphoma. Ann Intern Med 1997;127:423-428. 
5 de Sanjose S, Benavente Y, Vajdic CM, Engels EA, Morton LM, Bracci PM, Spinelli JJ, Zheng T, Zhang Y, Franceschi S, Talamini R, Holly EA, Grulich AE, Cerhan JR, Hartge P, Cozen W, Boffetta P, Brennan P, Maynadie M, Cocco P, Bosch R, Foretova L, Staines A, Becker N, Nieters A: Hepatitis C and nonHodgkin lymphoma among 4784 cases and 6269 controls from the international lymphoma epidemiology consortium. Clin Gastroenterol Hepatol 2008;6:451-458.

-6 Turner NC, Dusheiko G, Jones A: Hepatitis C and B-cell lymphoma. Ann Oncol 2003; 14: 1341-1345.

7 Mazzaro C, Franzin F, Tulissi P, Pussini E, Crovatto M, Carniello GS, Efremov DG, Burrone O, Santini G, Pozzato G: Regression of monoclonal B-cell expansion in patients affected by mixed cryoglobulinemia responsive to alpha-interferon therapy. Cancer 1996;77:2604-2613.

8 Caussin-Schwemling C, Schmitt C, StollKeller F: Study of the infection of human blood derived monocyte/macrophages with hepatitis C virus in vitro. J Med Virol 2001; 65:14-22.

$\triangleright_{9}$ Goutagny N, Fatmi A, De Ledinghen V, Penin F, Couzigou P, Inchauspe G, Bain C: Evidence of viral replication in circulating dendritic cells during hepatitis $C$ virus infection. J Infect Dis 2003;187:1951-1958.

10 Navas MC, Fuchs A, Schvoerer E, Bohbot A, Aubertin AM, Stoll-Keller F: Dendritic cell susceptibility to hepatitis $C$ virus genotype 1 infection. J Med Virol 2002;67:152-161.

11 Blackard JT, Kemmer N, Sherman KE: Extrahepatic replication of $\mathrm{HCV}$ : insights into clinical manifestations and biological consequences. Hepatology 2006;44:15-22.

12 Ducoulombier D, Roque-Afonso AM, Di Liberto G, Penin F, Kara R, Richard Y, Dussaix E, Feray C: Frequent compartmentalization of hepatitis $C$ virus variants in circulating $B$ cells and monocytes. Hepatology 2004;39: 817-825.

13 Morsica G, Tambussi G, Sitia G, Novati R, Lazzarin A, Lopalco L, Mukenge S: Replication of hepatitis $C$ virus in B lymphocytes (CD19+). Blood 1999;94:1138-1139.

14 Muller HM, Kallinowski B, Solbach C, Theilmann L, Goeser T, Pfaff E: B-lymphocytes are predominantly involved in viral propagation of hepatitis C virus (HCV). Arch Virol Suppl 1994;9:307-316.

-15 Ito M, Murakami K, Suzuki T, Mochida K, Suzuki M, Ikebuchi K, Yamaguchi K, Mizuochi T: Enhanced expression of lymphomagenesis-related genes in peripheral blood $\mathrm{B}$ cells of chronic hepatitis C patients. Clin Immunol 2010;135:459-465.

-16 Foy E, Li K, Wang C, Sumpter R Jr, Ikeda M, Lemon SM, Gale M Jr: Regulation of interferon regulatory factor-3 by the hepatitis $\mathrm{C}$ virus serine protease. Science 2003;300: $1145-1148$.
17 Foy E, Li K, Sumpter R Jr, Loo YM, Johnson CL, Wang C, Fish PM, Yoneyama M, Fujita T, Lemon SM, Gale M Jr: Control of antiviral defenses through hepatitis $\mathrm{C}$ virus disruption of retinoic acid-inducible gene-I signaling. Proc Natl Acad Sci USA 2005;102:29862991.

18 Dansako H, Ikeda M, Kato N: Limited suppression of the interferon-beta production by hepatitis $\mathrm{C}$ virus serine protease in cultured human hepatocytes. FEBS J 2007;274: 4161-4176.

19 Dansako H, Naka K, Ikeda M, Kato N: Hepatitis $\mathrm{C}$ virus proteins exhibit conflicting effects on the interferon system in human hepatocyte cells. Biochem Biophys Res Commun 2005;336:458-468.

20 Ikeda M, Sugiyama K, Mizutani T, Tanaka T, Tanaka K, Sekihara H, Shimotohno K, Kato $\mathrm{N}$ : Human hepatocyte clonal cell lines that support persistent replication of hepatitis C virus. Virus Res 1998;56:157-167.

21 Li K, Chen Z, Kato N, Gale M Jr, Lemon SM: Distinct poly(I-C) and virus-activated signaling pathways leading to interferon-beta production in hepatocytes. J Biol Chem 2005;280:16739-16747.

-22 Pattyn F, Robbrecht P, De Paepe A, Speleman F, Vandesompele J: RTPrimerDB: the realtime PCR primer and probe database, major update 2006. Nucleic Acids Res 2006;34(Database issue):D684-D688.

23 Imaizumi T, Yagihashi N, Kubota K, Yoshida $\mathrm{H}$, Sakaki H, Yagihashi S, Kimura H, Satoh $\mathrm{K}$ : Expression of retinoic acid-inducible gene-I (RIG-I) in macrophages: possible involvement of RIG-I in atherosclerosis. J Atheroscler Thromb 2007;14:51-55.

24 Xu J, Yang Y, Sun J, Ding Y, Su L, Shao C, Jiang B: Expression of Toll-like receptors and their association with cytokine responses in peripheral blood mononuclear cells of children with acute rotavirus diarrhoea. Clin Exp Immunol 2006;144:376-381.

25 Seth RB, Sun L, Chen ZJ: Antiviral innate immunity pathways. Cell Res 2006;16:141147.

26 Hiscott J, Pitha P, Genin P, Nguyen H, Heylbroeck C, Mamane Y, Algarte M, Lin R: Triggering the interferon response: the role of IRF-3 transcription factor. J Interferon $\mathrm{Cy}$ tokine Res 1999;19:1-13.

-27 Kawai T, Takahashi K, Sato S, Coban C, Kumar H, Kato H, Ishii KJ, Takeuchi O, Akira S: IPS-1, an adaptor triggering RIG-I- and Mda5-mediated type I interferon induction. Nat Immunol 2005;6:981-988.

28 Li XD, Sun L, Seth RB, Pineda G, Chen ZJ: Hepatitis C virus protease NS3/4a cleaves mitochondrial antiviral signaling protein off the mitochondria to evade innate immunity. Proc Natl Acad Sci USA 2005;102:1771717722 .
29 Fitzgerald KA, McWhirter SM, Faia KL, Rowe DC, Latz E, Golenbock DT, Coyle AJ, Liao SM, Maniatis T: IKKepsilon and TBK1 are essential components of the IRF3 signaling pathway. Nat Immunol 2003;4:491-496.

30 Huang J, Liu T, Xu LG, Chen D, Zhai Z, Shu HB: SIKE is an IKK epsilon/TBK1-associated suppressor of TLR3- and virus-triggered IRF-3 activation pathways. EMBO J 2005;24: 4018-4028.

- 31 Yang K, Shi H, Qi R, Sun S, Tang Y, Zhang B, Wang C: Hsp90 regulates activation of interferon regulatory factor 3 and TBK-1 stabilization in Sendai virus-infected cells. Mol Biol Cell 2006;17:1461-1471.

-32 Cordin O, Banroques J, Tanner NK, Linder $\mathrm{P}$ : The DEAD-box protein family of RNA helicases. Gene 2006;367:17-37.

33 Schroder M, Baran M, Bowie AG: Viral targeting of dead box protein 3 reveals its role in TBK1/IKKepsilon-mediated IRF activation. EMBO J 2008;27:2147-2157.

- 34 Soulat D, Burckstummer T, Westermayer S, Goncalves A, Bauch A, Stefanovic A, Hantschel O, Bennett KL, Decker T, SupertiFurga G: The DEAD-box helicase DDX3X is a critical component of the TANK-binding kinase 1-dependent innate immune response. ЕMBO J 2008;27:2135-2146.

35 Hamamoto I, Nishimura Y, Okamoto T, Aizaki H, Liu M, Mori Y, Abe T, Suzuki T, Lai MM, Miyamura T, Moriishi K, Matsuura Y: Human VAP-B is involved in hepatitis C virus replication through interaction with NS5A and NS5B. J Virol 2005;79:1347313482.

36 Loewen CJ, Levine TP: A highly conserved binding site in vesicle-associated membrane protein-associated protein (VAP) for the FFAT motif of lipid-binding proteins. J Biol Chem 2005;280:14097-14104.

37 Nishimura Y, Hayashi M, Inada H, Tanaka T: Molecular cloning and characterization of mammalian homologues of vesicle-associated membrane protein-associated (VAMPassociated) proteins. Biochem Biophys Res Commun 1999;254:21-26.

38 Kukihara H, Moriishi K, Taguwa S, Tani H, Abe T, Mori Y, Suzuki T, Fukuhara T, Taketomi A, Maehara Y, Matsuura Y: Human VAP-C negatively regulates hepatitis $C$ virus propagation. J Virol 2009;83:7959-7969.

- 39 Miyazaki M, Kanto T, Inoue M, Itose I, Miyatake H, Sakakibara M, Yakushijin T, Kakita N, Hiramatsu N, Takehara T, Kasahara A, Hayashi N: Impaired cytokine response in myeloid dendritic cells in chronic hepatitis $C$ virus infection regardless of enhanced expression of Toll-like receptors and retinoic acid inducible gene-I. J Med Virol 2008;80: 980-988.

40 Ariumi Y, Kuroki M, Abe K, Dansako H, Ikeda M, Wakita T, Kato N: DDX3 DEAD-box RNA helicase is required for hepatitis $C$ virus RNA replication. J Virol 2007;81:1392213926. 
-41 Tu H, Gao L, Shi ST, Taylor DR, Yang T, Mircheff AK, Wen Y, Gorbalenya AE, Hwang SB, Lai MM: Hepatitis C virus RNA polymerase and NS5A complex with a SNARElike protein. Virology 1999;263:30-41.

- 42 Zuckerman E, Zuckerman T, Sahar D, Streichman S, Attias D, Sabo E, Yeshurun D, Rowe J: bcl-2 and immunoglobulin gene rearrangement in patients with hepatitis $\mathrm{C}$ virus infection. Br J Haematol 2001;112:364369.

-43 Zignego AL, Giannelli F, Marrocchi ME, Mazzocca A, Ferri C, Giannini C, Monti M, Caini P, Villa GL, Laffi G, Gentilini P: t(14; 18) translocation in chronic hepatitis $C$ virus infection. Hepatology 2000;31:474-479.
44 Komeno Y, Kitaura J, Watanabe-Okochi N, Kato N, Oki T, Nakahara F, Harada Y, Harada $\mathrm{H}$, Shinkura R, Nagaoka $\mathrm{H}$, Hayashi $\mathrm{Y}$, Honjo T, Kitamura T: AID-induced T-lymphoma or B-leukemia/lymphoma in a mouse BMT model. Leukemia 2010;24:1018-1024.

45 Robbiani DF, Bunting S, Feldhahn N, Bothmer A, Camps J, Deroubaix S, McBride KM, Klein IA, Stone G, Eisenreich TR, Ried T, Nussenzweig A, Nussenzweig MC: AID produces DNA double-strand breaks in non-Ig genes and mature B cell lymphomas with reciprocal chromosome translocations. Mol Cell 2009;36:631-641.

46 Ray RB, Meyer K, Ray R: Suppression of apoptotic cell death by hepatitis $C$ virus core protein. Virology 1996;226:176-182.
47 Sakamuro D, Furukawa T, Takegami T: Hepatitis $C$ virus nonstructural protein NS3 transforms NIH 3T3 cells. J Virol 1995;69: 3893-3896.

48 Machida K, Cheng KT, Pavio N, Sung VM, Lai MM: Hepatitis C virus E2-CD81 interaction induces hypermutation of the immunoglobulin gene in B-cells. J Virol 2005;79: 8079-8089.

49 Stamataki Z, Shannon-Lowe C, Shaw J, Mutimer D, Rickinson AB, Gordon J, Adams DH, Balfe P, McKeating JA: Hepatitis C virus association with peripheral blood B lymphocytes potentiates viral infection of liver-derived hepatoma cells. Blood 2009;113:585593. 